\title{
Fecal Microbiota Transplantation for Refractory Clostridioides Difficile Infection Is Effective and Well Tolerated Even in Very Old Subjects: A Real- Life Study
}

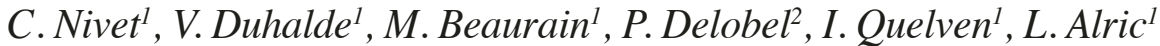 \\ 1. Hôpital de Rangueil, Toulouse, France; 2. Université Toulouse III Paul Sabatier, Toulouse, France
}

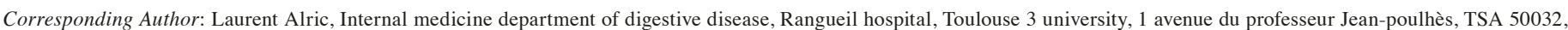
31000 Toulouse,France, alric.1@chu-toulouse.fr

\begin{abstract}
OBJECTIVES: Fecal microbiota transplantation (FMT) is an innovative therapy indicated for the treatment of recurrent Clostridioides difficile infections. Although CDI and its complications are more common in very old patients ( $\geq 80$ years) due to their comorbidities, frailty and senescence of the immune system, limited data are available for this older patient population.

DESIGN: This was a single-center, real-life cohort study with retrospective outcome data registration, conducted at Toulouse, France. SETTING AND PARTICIPANTS: Older people group was compared to the control group aged $18-79$ years.

MEASUREMENTS: The primary outcome was overall survival at 52 weeks for $\geq 80$ years patients compared to the control group after FMT. Recurrence-free survival at 52 weeks and, the occurrence of adverse events in the short and long term were the secondary endpoints.

RESULTS: A total of 58 patients were included, 19 were aged $\geq 80$ years and 39 were aged 18-79 years. Overall survival at 52 weeks after FMT of the very old patients was not different from the control group (78.9\% versus $89.7 \%, p=0.29$ ). Recurrence-free survival of CDI was not different between groups, with $94.3 \%$ in the 18-79-group versus $86.9 \%$ in the $\geq 80$ group ( $\mathrm{p}=0.44$ ). The occurrence of short- or longterm adverse events was not statistically different between the two groups $(36.8 \%$ vs $41 \%, \mathrm{p}=0.45)$.

CONCLUSIONS: FMT is effective and well-tolerated in very old frail patients. This treatment brings a rapid benefit and limits the loss of functions. It also favors their maintenance at home or in a non-medical institution dedicated to dependent subjects and improves their quality of life.
\end{abstract}

Key words: Fecal microbiota transplantation, clostridioides difficile infection, frailty, older people.

\section{Introduction}

$\mathrm{F}$ lecal microbiota transplantation (FMT) is an innovative therapy indicated for the treatment of recurrent, severe or refractory Clostridioides difficile infections (CDI) $(1,2)$ and looks promising in other indications (3).

$\mathrm{CDI}$ is the most common cause of healthcare associated infection $(1,4)$. CDI is also found in the community and institutional wards. It is a major public health problem, responsible for an increase in hospitalizations, deaths and health care expenditure (5).
Many risk factors for infection have been identified and are more frequently found in the older people including hospitalisation, exposure to chemotherapy, antibiotic therapy and proton pump inhibitor (PPI) therapy (1). The majority of deaths attributable to Clostridium difficile occur in older people and, comorbid patients. The severity and recurrence of CDI are also more common in this population $(5,6)$. Recurrence of infection occurs in approximately $10-30 \%$ after appropriate antibiotic treatment, and increases after each recurrence, posing a real therapeutic challenge (7).

Older people are preferential candidates for FMT. Although very effective, this technique is still poorly understood by practitioners. Few studies have been conducted in the old population aged $\geq 65$ years (8-10), showing the effectiveness and good tolerance of FMT. The frailty and comorbidities of an older patient may represent a barrier to the use of this treatment. Although CDI and its complications are more common in very old patients ( $\geq 80$ years) due to their comorbidities, frailty and senescence of the immune system, limited data are available for this very old population (11).

The aim of this study was to evaluate the survival rate, efficacy and safety of FMT in very old frail patients.

\section{Method}

\section{Study design}

This was a single-center, cohort study with retrospective outcome data registration, real-life study conducted at the Toulouse University Hospital. The study protocol was approved by the French Regional Agency and by the research committee of the center (the Clinical Research Department of the Toulouse University Hospital) and registered in 2020. Individual information was provided to eligible persons and respects the « data processing and freedoms " rights according to articles 13 and 14 of the RGPD (registration number: RnIPH 202094). The objective of the study was to evaluate the efficacy and safety of FMT in very old patients ( $\geq 80$ years) compared to the control group (18-79 years). 


\section{Study population}

Patients were prospectively and consecutively included in the center's FMT register between 28/10/2015 and 12/03/2020. Inclusion criteria were age $\geq 18$ years and having received FMT for recurrent CDI. Patients treated for another indication were not included. Exclusion criteria were a follow-up time of fewer than 6 months post-FMT and insufficient data collection. The cohort was separated into 2 age groups. A control group aged $18-79$ years and a group of very old patients ( $\geq 80$ years).

\section{Processing of donor feces preparations}

Fecal transplantation activity has been in place since 2015 in our center. Donor selection and donation preparation were performed under the responsibility of the in-house pharmacy. Donors were healthy anonymous adult volunteers carefully screened according to the recommendations of the French National Drug Safety Agency (ANSM) (13), the French Fecal Transplant Group (GFTF) (14), and from the end of 2019 the European recommendations (2). Briefly, all donors had a normal body mass index, no medical history, no use of medication in the preceding 6 months, no trip abroad in the previous 3 months, and a normal physical examination. In addition, the blood and the stools of all donors were examined for common biological tests and screened for pathogens according to guidelines $(13,14)$.

A fecal suspension was generated in isotonic saline solution with $10 \%$ of glycerol under aerobic conditions. Donation of feces was done on-site and approximately $50 \mathrm{gr}$ of stool was required for each treatment. The definitive mixture was aliquoted with $200 \mathrm{~mL}$ of stool suspension and immediately frozen at $-80^{\circ} \mathrm{C}$ in individual samples. In some cases, we distributed the obtained preparation by concentrating it in 50 capsules frozen at $-80^{\circ} \mathrm{C}$.

Patients were treated with vancomycin for at least $72 \mathrm{~h}$ and up to $48 \mathrm{~h}$ before the procedure. In case of administration by nasoduodenal tube or colonoscopy or capsules, they received an intestinal preparation with $1 \mathrm{~L}$ of polyethylene glycol. The route of administration was left to the discretion of the clinician (nasoduodenal tube, enema, colonoscopy or capsules) taking into account the patient's condition.

\section{Baseline and follow up}

Demographic, CDI and FMT data were collected from paper and digital medical and paramedical records. Comorbidities (e.g., diabetes, neoplasia) were recorded by the Charlson score (15). Polypharmacy was defined as taking at least 5 drugs daily (16). Biological data at the time of FMT were collected. The history of Clostridium difficile infection (e.g., number of recurrences, contributing factors, treatment sequence, form of last episode), data on FMT (e.g., route of administration, donorrecipient compatibility) were reported. CDI were characterized according to the definitions given by IDSA (4) and ESCMID (1). The realization of a second FMT was noted. Frailty scores were assessed at the time of FMT to identify frail patients among the young older (aged $\geq 65$ years) and the old older (aged $\geq 80$ years). The Rockwood scale and the modified Rockwood index $(7,8)$ were used. These scores are based on medicalpsycho-social assessments. The Rockwood scale is a clinical score ranging from 1 (very well) to 9 (terminally ill). The Rockwood frailty index quantifies deficits (presence of disease, ability in activities of daily living and clinical signs). The sum of the deficits present was added to the total number of deficits considered. 45 criteria were assessed for the calculation of the index. Motor assessment, family history, memory and psychiatric disorders were not recorded as they were often not detailed in the files. Follow-up and survival data were collected up to February 2021 by a call from the patient or their general practitioner at 52 weeks and supplemented by consultation of the hospital medical record and death register. The primary endpoint was overall survival at 52 weeks for the oldest patients compared to the control group after FMT. Overall survival included all-cause deaths within one year of FMT. Recurrencefree survival at 52 weeks, the occurrence of adverse events in the short term (within 72 hours post-procedure) and in the long term (within 52 weeks) were the secondary endpoints. Recurrence was defined as the presence of diarrhea ( $>3$ stools per day) associated with a positive Clostridioides difficile toxin test. Patients lost to follow-up or who died before 52 weeks in the absence of the event were censored.

\section{Other measurements}

A secondary analysis comparing patients aged $\geq 75$ years to 18-74 years was performed. The efficacy and safety of FMT were assessed in these two groups. An association between age and the occurrence of the primary and secondary endpoints was sought.

\section{Statistics}

Descriptive statistics were performed for each group. Categorical variables were assessed by percentages. Continuous variables were assessed by the median. Univariate analysis using the Wilcoxon rank sum test for continuous variables and the chi-square test or Fisher's exact test for categorical variables was used to search for an association between age and the occurrence of the endpoints. The search for an association was carried out by logistic regression analysis. A subgroup analysis was performed for the analysis of frailty scores (65-79 years versus $\geq 80$ years). Overall and recurrence-free survival curves were analyzed by the log rank test. SAS version 9.4 software was used for univariate analyses and logistic regression, and PRISM 6 software for survival curves. A two-sided threshold of $\mathrm{p}<0.05$ was considered statistically significant. 
Table 1. Clinical and biological characteristics of patients at the time of FMT

\begin{tabular}{|c|c|c|c|}
\hline & $18-79$ & $\geq 80$ & $\mathbf{p}$ \\
\hline $\mathrm{n}$ & 39 & 19 & \\
\hline Women $(\%)$ & $26(66.7)$ & $13(68.4)$ & 0.89 \\
\hline Age & $62[49 ; 71]$ & $84[83 ; 90]$ & $<0.001$ \\
\hline \multicolumn{4}{|l|}{ Comorbidities } \\
\hline Charlson score & $4[2 ; 8]$ & $7[6 ; 9]$ & 0.005 \\
\hline High blood pressure & $13(33.3)$ & $12(63.2)$ & 0.05 \\
\hline Neoplasia & $14(35.9)$ & $3(15.8)$ & 0.11 \\
\hline Renal failure & $7(17.9)$ & $11(57.9)$ & 0.002 \\
\hline Irritable bowel Syndrome & $3(7.7)$ & 0 & 0.54 \\
\hline Intestinal bowel disease & $4(10.3)$ & 0 & 0.29 \\
\hline Hemopathy & $3(7.7)$ & $3(15.8)$ & 0.38 \\
\hline Chemotherapy & $5(13.2)$ & 0 & 0.16 \\
\hline HIV & $2(5.1)$ & 0 & 1 \\
\hline Organ transplant & $4(10.3)$ & 0 & 0.29 \\
\hline Immunosuppressive agent & $6(15.4)$ & 0 & 0.16 \\
\hline Cirrhosis & $2(5.1)$ & $1(5.3)$ & 1 \\
\hline Diabetes & $2(5.1)$ & $5(26.3)$ & 0.03 \\
\hline \multicolumn{4}{|l|}{ Therapy } \\
\hline Polypharmacy & $24(61.5)$ & $17(89.5)$ & 0.03 \\
\hline Proton pump inhibitor & $12(30.8)$ & $6(31.6)$ & 0.95 \\
\hline ATB before CDI & $24(63.2)$ & $14(77.8)$ & 0.27 \\
\hline \multicolumn{4}{|l|}{ Biology before FMT } \\
\hline $\mathrm{CRP}(\mathrm{mg} / \mathrm{L})^{\mathrm{a}}$ & $2.6[1 ; 13.6]$ & $23.5[3.25 ; 40.7]$ & 0.01 \\
\hline $\mathrm{WBC}(\mathrm{G} / \mathrm{L})^{\mathrm{b}}$ & $6.66[5.41 ; 8.34]$ & $8.19[5.82 ; 9.72]$ & 0.29 \\
\hline $\operatorname{Alb}(\mathrm{g} / \mathrm{L})^{\mathrm{c}}$ & $33[31 ; 40]$ & $29.1[24 ; 32]$ & 0.04 \\
\hline Creatinine $(\mu \mathrm{g} / \mathrm{L})^{\mathrm{d}}$ & $68.4[56 ; 82]$ & $85[62 ; 119]$ & 0.11 \\
\hline $\mathrm{Hb}(\mathrm{g} / \mathrm{dL})^{\mathrm{e}}$ & $11.7[10.8 ; 13.1]$ & $11[9.7 ; 12.9]$ & 0.18 \\
\hline
\end{tabular}

a. 11 missing data ( 3 for $\geq 80$ years); b. 8 missing data ( 1 for $\geq 80$ years); c. 30 missing data ( 10 for $\geq 80$ years); d. 10 missing data ( 2 for $\geq 80$ years); e. 7 missing data ( 1 for $\geq 80$ years)

\section{Results}

\section{Population}

A total of 58 patients were included in this study 19 were $\geq 80$ years old and 39 were $18-79$ years old. Table 1 shows the clinical and biological characteristics of the 2 groups at the time of FMT. The median age of the oldest patients was 84 years. The oldest patients were aged 95 years. The median age in the control group (18-79 years) was 62 years. The oldest patients had more comorbidities than the control group, with a median Charlson score of 7 versus $4(\mathrm{p}=0.003)$. Frailty scores for patients aged $\geq 80$ years were twice as high at the time of FMT as those aged 65-79 years. The median Rockwood scale score was $6[4 ; 6]$ versus $3[3 ; 4]$ respectively $(\mathrm{p}=0.007)$ and the median Rockwood index was 0.311 [0.178; 0.489$]$ versus 0.156 $[0.111 ; 0.178]$ respectively $(\mathrm{p}=0.02)$. Polypharmacy was higher in the oldest group ( $89.4 \%$ versus $61.5 \%, \mathrm{p}=0.03$ ). Risk factors for CDI were reported. Just under a third of patients were taking PPI in both groups before FMT. About $37 \%$ of patients aged 18-79 years and $23 \%$ of those $\geq 80$ years had not taken an antibiotic before CDI. An immunosuppressive factor (organ transplantation, chemotherapy and IBD in particular) was more often found in the younger age groups for 18-79 years, without reaching the significance threshold. This difference was significant when comparing the 18-74 years group to the $\geq 75$ years group. At the time of the first episode of CDI, antibiotic therapy was reported evenly between the 2 groups (77.8\% and 63.2\%, $\mathrm{p}=0.27$ ). CRP measured $<72 \mathrm{~h}$ before FMT was higher in the $\geq 80$ group compared to the $18-79$ years group $(23.5 \mathrm{mg} / \mathrm{L}$ versus $<5 \mathrm{mg} / \mathrm{L}, \mathrm{p}=0.01$ ) while $\mathrm{WBC}$ count was not significantly different between the 2 groups.

\section{CDI characteristics and treatments received}

The median number of recurrences before FMT was 3 in both groups (Table 2). The lines of treatment received were comparable between the 2 groups. Fidaxomicin was more often 


\begin{tabular}{|c|c|c|c|}
\hline CDI characteristics & 18-79 & $\geq 80$ & p-value \\
\hline IPP & $12(30)$ & $6(33)$ & 1 \\
\hline Number of relapses before FMT & $3[2 ; 3]$ & $3[3 ; 4]$ & 0.21 \\
\hline \multicolumn{4}{|l|}{ Prior treatments } \\
\hline Metronidazole & $31(83.8)$ & $17(89.5)$ & 0.70 \\
\hline Fidaxomicin & $25(67.6)$ & $10(52.6)$ & 0.27 \\
\hline Vancomycin & $35(94.6)$ & $18(94.7)$ & 1 \\
\hline Pulsed vancomycin & $10(27)$ & $6(31.6)$ & 0.72 \\
\hline \multicolumn{4}{|l|}{$\begin{array}{l}\text { FMT characteristics } \\
\text { Serocompatibility }\end{array}$} \\
\hline Cytomegalovirus $^{\mathrm{c}}$ & $37(97.4)$ & $17(89.5)$ & 0.25 \\
\hline Toxoplasmosise $^{\mathrm{d}}$ & $35(100)$ & $17(100)$ & 1 \\
\hline Epstein Barr virus & $36(97.3)$ & $16(100)$ & 1 \\
\hline \multicolumn{4}{|l|}{ FMT route } \\
\hline Naso-duodenal & $36(92.3)$ & $10(52.6)$ & 0.001 \\
\hline Coloscopy & 0 & $1(5.3)$ & 0.33 \\
\hline Rectoscopy & $2(5.1)$ & $5(26.3)$ & 0.03 \\
\hline
\end{tabular}

a. 2 missing data; b. 1 missing data; c. 1 missing data; d. 6 missing data; e. 4 missing data; f. 1 missing data in the 18-79 years group.

prescribed in younger patients, with a significant difference when comparing $\geq 75$ years to $18-74$ years $(77.4 \%$ versus $44 \%$, $\mathrm{p}=0.01)$. There were few severe infections, only 1 in the very old patients, with no statistical difference between the groups.

Donor-recipient serocompatibility for CMV, toxoplasmosis and EBV was similar between the 2 groups. Transplantation was administered by the lower route (rectoscopy, enema, colonoscopy) in $47.4 \%$ in $\geq 80$ years-old patients, compared with $5.1 \%$ in younger patients. The nasogastric tube was the most frequently used route, $52.6 \%$ in the $\geq 80$-year-olds versus $92.3 \%$ with a significant difference between the 2 groups $(\mathrm{p}=0.001)$. Only one patient in the cohort received capsule FMT, this technique being available at the end of the study in our center. The choice of technique was adapted at the time of FMT for some patients. One very old patient had a pyloric stenosis discovered during the nasogastric tube placement. The administration could be done by enema. The average length of stay in hospital for FMT was not different between the two groups.
Figure 1. Overall survival at 52 weeks of patients aged $\geq 80$ years compared to $18-79$ years

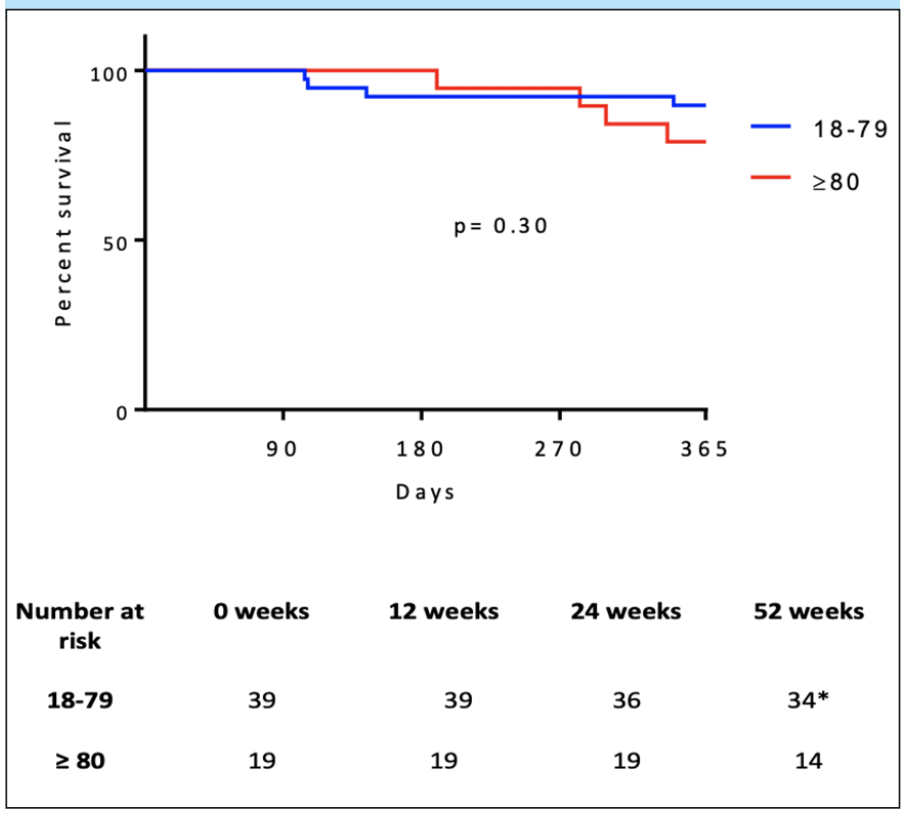

* Censored $(\mathrm{n}=1)$ : Event not occurring at 314 days follow up. 
Table 3. Occurrence of secondary endpoints

\begin{tabular}{|c|c|c|c|}
\hline & 18-79 & $\geq 80$ & p-value \\
\hline ICD relapse & $5(14.3)$ & $4(23.5)$ & 0.45 \\
\hline Second FMT & $2(40)$ & 0 & 0.46 \\
\hline Second FMT Cure & $2(100)$ & 0 & N/A \\
\hline Any adverse event & $16(41)$ & $7(36.8)$ & 0.76 \\
\hline Early ardverse event & 7 (17.9) & $6(31.6)$ & 0.32 \\
\hline Diarrhea & $3(7.7)$ & $3(15.8)$ & 1 \\
\hline Vomiting & $2(5.1)$ & 0 & 1 \\
\hline Abdominal pain & $4(10.3)$ & 0 & 0.29 \\
\hline Sepsis & 0 & $1(5.3)$ & 0.33 \\
\hline Psychiatric collapse & 0 & $1(5.3)$ & 0.33 \\
\hline Late adverse event & $11(28.2)$ & $1(10.5)$ & 0.19 \\
\hline Diarrhea & $4(10.3)$ & 0 & 0.29 \\
\hline Abdominal pain & $3(7.7)$ & $1(5.3)$ & 1 \\
\hline Constipation & $3(7.7)$ & 0 & 0.54 \\
\hline Intestinal bowel disease & 0 & $1(5.3)$ & 0.33 \\
\hline Sepsis & $1(2.6)$ & 0 & 1 \\
\hline Psychiatric collapse & $2(5.1)$ & 0 & 1 \\
\hline Serious adverse event & $2(5.1)$ & $2(10.5)$ & 0.59 \\
\hline Sepsis & 1 & 1 & 0.33 \\
\hline Severe psychiatric collapse & 1 & 0 & 1 \\
\hline Intestinal bowel disease & 0 & 1 & 0.33 \\
\hline
\end{tabular}

\section{Figure 2. CDI recurrence-free survival of groups at 52 weeks}

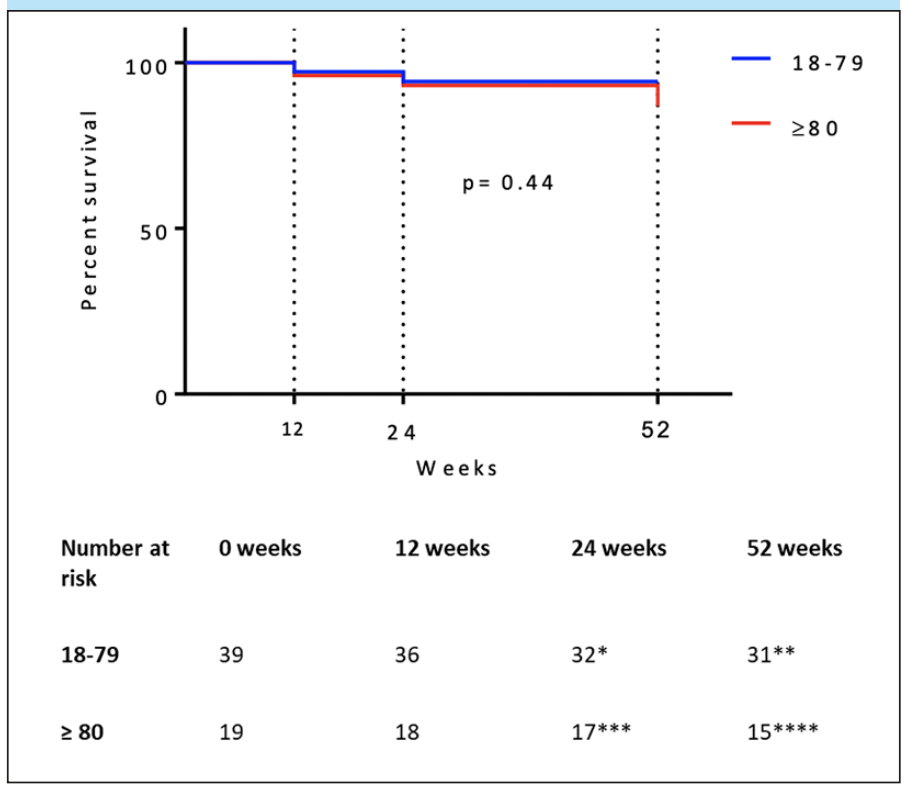

$* 2$ deaths ; **1 death; $* * * 1$ death; $* * * * 1$ death

\section{Primary efficacy endpoint}

Overall survival at 52 weeks after FMT of the oldest patients was not different from the control group (Figure 1). It was $78.9 \%$ in the $\geq 80$ years group versus $89.7 \%$ in the $18-79$ years group $(\mathrm{p}=0.29)$. Four deaths were reported in each group during follow-up. None were related to FMT.

\section{Secondary efficacy endpoint}

Recurrence-free survival (Figure 2) of CDI was not different between groups, $94.3 \%$ in the $18-79$ years group versus $86.9 \%$ in the $\geq 80$ years group ( $\mathrm{p}=0.44$ ). At 52 weeks (Table 3 ), $23.5 \%$ of patients $\geq 80$ years had relapsed versus $11.8 \%$ of younger patients $(\mathrm{p}=0.45)$. The occurrence of short or long-term adverse events was not statistically different between the 2 groups (36.8\% vs $41 \%, \mathrm{p}=0.45$ ). The majority of events were mild to moderate (diarrhea, abdominal pain, vomiting, constipation).

Two severe events were reported in both groups. An 83-years-old diabetic man with polyvascular disease treated with Imatinib for chronic lymphocytic leukemia developed undocumented sepsis within 24 hours of FMT, resulting in a 15-day extension of hospital stay. This event was linked to the procedure by a probable translocation mechanism. Among the late events, a 59-years-old female patient presented a severe psychiatric decompensation with a suicide attempt following FMT. A Clostridiodes difficile septic shock leading to death was reported in a 66-years-old patient, 104 days after FMT. This event was related to a failure of FMT not to the procedure. Inflammatory bowel disease (IBD) was diagnosed 3 months after transplantation in an 85-years-old patient. He had preexisting abdominal disorders associated with myelodysplastic 
syndrome. FMT was ruled out as a cause. An extrahematological manifestation of the myelodysplastic syndrome was retained. This patient died at age 89, 4 years after FMT.

There was no association between age and the occurrence of primary and secondary endpoints in logistic regression.

\section{Discussion}

FMT is a major therapy in the management of CDI recognized by all international guidelines. Very old patients are particularly at risk of CDI but are under-represented in studies. To our knowledge, there have been no targeted analyses of the safety and efficacy of FMT among the $\geq 80$ years age group. In clinical practice, this innovative therapy is not yet sufficiently proposed to the oldest patients, due to lack of knowledge but also to fear of invasive procedures. In this real-life cohort study with retrospective outcome data registration, we analyzed the efficacy and tolerance of FMT in very old ( $\geq 80$ years), comorbid (mean Charlson score 7) and frail (mean 6 on the Rockwood scale) patients.

Nearly $89 \%$ of the oldest patients had been treated with metronidazole at the time of the initial episode, whereas vancomycin is more commonly recommended (1). Despite its particular benefits to this population at risk of recurrence, access to this treatment remains an obstacle to its use due to the need for pharmacists to prepare capsules, or use of the intravenous oral formulation. CDI impairs quality of life and leads to loss of function in frail older people. In our study, FMT intervened on average after a $3 r d$ recurrence in those aged $\geq 80$ years, with no significant difference from the control group. Early treatment with FMT in this population could limit their loss of function.

The recurrence-free survival reported in our study agree with the literature. However, studies conducted in the older people have a shorter follow-up time than our cohort. Girotra et al. (8), reported efficacy of $93.1 \%$ in an old population with fewer comorbidities and less frailty than in our cohort. Friedman-Korn et al (10) in a small cohort of comorbid old patients reported an early recovery rate of $86 \%$. This rate is similar to our long-term follow-up results (52 weeks).

The overall survival of the oldest patients at 52 weeks was close to $79 \%$ and was not significantly different from younger patients. The advanced age and frailty of a patient should not rule out treatment with FMT. Quality of life and performance after FMT was not quantified during follow-up but improvement was frequently reported. Of the 4 patients aged $\geq 90$ years, one 92-year-old woman died 1.5 years after FMT and had been maintained at home. A 90-years-old patient died 190 days after FMT. Another patient aged 95 who had a late failure of FMT, was alive at 52 weeks. A 95-years-old man died of acute myeloid leukemia 340 days after transplantation. This patient had an early failure at 1 week after a technically difficult FMT (failure of SNG placement and impassable rectal ampulla). Despite the early recurrence of CDI, clinical improvement was noted in this patient.

CDI is a major problem in nursing homes. Of the 293,300 cases of nosocomial CDI reported in a large US study in 2011,
104,400 were acquired in nursing homes (6). When it occurs in a nursing home, CDI is responsible for social isolation and may lead to exclusion from the nursing home due to hygiene constraints or the extent of diarrhea. Faced with distraught families, this possibility of exclusion has sometimes motivated the performance of FMT in old and frail patients.

Short-term adverse events were few and similar to those described in the literature (17). Only one severe event related to the procedure was reported in an 83-years-old immunocompromised patient with polyvascular disease. He presented with fever and elevated inflammatory markers. This undocumented septic episode resolved spontaneously. This is a rare event reported in immunocompromised patients like our patient (18).

There were no more events in patients $\geq 80$ years of age. In the long term, only one patient aged $\geq 80$ years reported fluctuating abdominal pain without frank alteration of her quality of life. One 84-years-oldpatient presented with a brief confusional episode after nasogastric tube placement and before transplant administration. She was treated by enema. The transplant can be administered by nasogastric tube, colonoscopy, enema, freeze-dried or frozen capsule. These different methods of administration have all been shown to be effective. The ideal route is the one adapted to the patient and mastered by the local team (19). The possibility of adaptation is essential in older people who more often have swallowing disorders and cognitive problems.

In recent years, FMT has undergone drastic technical improvements. The conditioning of transplants with donations stored at $-80^{\circ} \mathrm{C}$ allows FMT to be performed in any hospital and even at home as shown by Jørgensen et al (11). It is not essential to perform FMT in an FMT center in all cases. The latest European consensus is in line with this. Stool banks are being developed throughout Europe and will allow widespread access to this treatment. The administration of donor feces suspension is simple and can be performed by any qualified health professional. This effective and well-tolerated therapy in frail patients aged $\geq 80$ years should be offered and accessible to this population. Covid-19 has led to new expert recommendations (20) to ensure the safety of FMT. This reorganization has limited the increase in transplants stocks and thus temporarily the accessibility of this treatment.

Limitations of this study include the small number of patients aged $\geq 80$ years, the monocentric and retrospective outcome data registration nature inducing a recall bias for late adverse events and a measurement bias related to the collection in the records.

In summary, FMT is effective and well-tolerated in very old frail patients. This treatment brings a rapid benefit and limits the loss of functions. Also, it favors their maintenance at home or in a non-medical institution dedicated to dependent subjects and improves their quality of life. An evaluation of the performance of older patients could guide the optimal treatment and allow this treatment to be offered earlier.

Acknowledgements: We thank Gregory Pugnet, Pauline Floch, Florence Abravanel, Mathieu Tafani, Delphine Bonnet, Marion Godart, Félix Guinard-Brun, Manon Schouler and donors. 
Authors contributions: Caroline Nivet and Laurent Alric meet all the the criteria for authorship which include: substantial contributions to conception and design, or acquisition of data, or analysis and interpretation of data, drafting the article or revising it critically for important intellectual content final approval of the version to be published; and agreement to be accountable for all aspects of the work. Véronique Duhalde, Marie Beaurain, Pierre Delobel and Isabelle Quelven participated to conception and design, or acquisition of data.

Conflicts of interests: none

Funding: none

Ethical standards: The study was carried out according the French Regional Agency and by the research committee of the center with informed consent.

\section{References}

1. McDonald LC, Gerding DN, Johnson S, Bakken JS, Carroll KC, Coffin SE, et al Clinical Practice Guidelines for Clostridium difficile Infection in Adults and Children: 2017 Update by the Infectious Diseases Society of America (IDSA) and Society for Healthcare Epidemiology of America (SHEA). Clin Infect Dis Off Publ Infect Dis Soc Am 2018;66: e1-48. doi: 10.1093/cid/cix1085.

2. Cammarota G, Ianiro G, Tilg H, Rajilić-Stojanović M, Kump P, Satokari R, et al European consensus conference on faecal microbiota transplantation in clinical practice. Gut 2017; 66:569-80. doi: 10.1136/gutjnl-2016-313017.

3. Ooijevaar RE, Terveer EM, Verspaget HW, Kuijper EJ, Keller JJ. Clinical Application and Potential of Fecal Microbiota Transplantation. Annu Rev Med 2019; 70:335-51. doi: 10.1146/annurev-med-111717-122956.

4. Debast SB, Bauer MP, Kuijper EJ. European Society of Clinical Microbiology and Infectious Diseases: update of the treatment guidance document for Clostridium difficile infection. Clin Microbiol Infect 2014; 20:1-26. doi: 10.1111/1469. 0691.12418

5. Leffler DA, Lamont JT. Clostridium difficile infection. N Engl J Med 2015; 372:1539_ 48. doi: 10.1056/NEJMra1403772.

6. Lessa FC, Mu Y, Bamberg WM, Beldavs ZG, Dumyati GK, Dunn JR, et al. Burden of Clostridium difficile Infection in the United States. N Engl J Med 2015;372:825-34. doi: 10.1056/NEJMoa1408913.

7. Fekety R, McFarland LV, Surawicz CM, Greenberg RN, Elmer GW, Mulligan ME. Recurrent Clostridium difficile diarrhea: characteristics of and risk factors for patients enrolled in a prospective, randomized, double-blinded trial. Clin Infect Dis Off Publ Infect Dis Soc Am 1997;24:324-33. doi: 10.1093/clinids/24.3.324.

8. Girotra M, Garg S, Anand R, Song Y, Dutta SK. Fecal Microbiota Transplantation for Recurrent Clostridium difficile Infection in the Elderly: Long-Term Outcomes and Microbiota Changes. Dig Dis Sci 2016;61:3007-15. doi: 10.1007/s10620-016-4229-8.
9. Agrawal M, Aroniadis OC, Brandt LJ, Kelly C, Freeman S, Surawicz C, et al. The Long-term Efficacy and Safety of Fecal Microbiota Transplant for Recurrent, Severe, and Complicated Clostridium difficile Infection in 146 Elderly Individuals. J Clin Gastroenterol. 2016 May-Jun;50(5):403-7. doi: 10.1097/MCG.0000000000000410.

10. Friedman-Korn T, Livovsky DM, Maharshak N, Aviv Cohen N, Paz K, Bar-Gil Shitrit A, et al. Fecal Transplantation for Treatment of Clostridium Difficile Infection in Elderly and Debilitated Patients. Dig Dis Sci 2018;63:198-203. doi : 10.1007/s10620017-4833-2.

11. Jørgensen SMD, Rubak TMM, Damsgaard EM, Dahlerup JF, Hvas CL. Faecal microbiota transplantation as a home therapy to frail older people. Age Ageing 2020;49:1093-6. doi: 10.1093/ageing/afaa073.

12. ANSM. La transplantation de microbiote fécal et son encadrement dans les essais cliniques. 2015.

13. Sokol H, Galperine T, Kapel N, Bourlioux P, Seksik P, Barbut F, et al. Faecal microbiota transplantation in recurrent Clostridium difficile infection: Recommendations from the French Group of Faecal microbiota Transplantation. Dig Liver Dis Off J Ital Soc Gastroenterol Ital Assoc Study Liver 2016; 48:242-7. doi: 10.1016/j.dld.2015.08.017

14. Charlson ME, Pompei P, Ales KL, MacKenzie CR. A new method of classifying prognostic comorbidity in longitudinal studies: Development and validation. J Chronic Dis 1987; 40:373-83. doi: 10.1016/0021-9681(87)90171-8.

15. World Health Organization. Medication Safety in Polypharmacy. 2019

16. Rockwood K, Song X, MacKnight C, Bergman H, Hogan DB, McDowell I, et al. A global clinical measure of fitness and frailty in elderly people. CMAJ Can Med Assoc J 2005; 173:489-95. doi: 10.1503/cmaj.050051.

17. Cammarota G, Ianiro G, Gasbarrini A. Fecal microbiota transplantation for the treatment of Clostridium difficile infection: a systematic review. J Clin Gastroentero 2014; 48:693-702. doi: 10.1097/mcg.0000000000000046.

18. Di Bella S, Gouliouris T, Petrosillo N. Fecal microbiota transplantation (FMT) for Clostridium difficile infection: focus on immunocompromised patients. J Infect Chemother Off J Jpn Soc Chemother 2015; 21:230-7. doi:10.1016/j.jiac.2015.01.011.

19. Keller JJ, Ooijevaar RE, Hvas CL, Terveer EM, Lieberknecht SC, Högenauer C, et al. A standardised model for stool banking for faecal microbiota transplantation: a consensus report from a multidisciplinary UEG working group. United Eur Gastroenterol J 2021 Mar;9(2):229-247. doi: 10.1177/2050640620967898.

20. Ianiro G, Mullish BH, Kelly CR, Kassam Z, Kuijper EJ, Ng SC, et al. Reorganisation of faecal microbiota transplant services during the COVID-19 pandemic. Gut 2020 69:1555-63. doi: 10.1136/gutjnl-2020-321829.

How to cite this article: Nivet, C., Duhalde, V., Beaurain M., et al. Fecal Microbiota Transplantation for Refractory Clostridioides Difficile Infection Is Effective and Well Tolerated Even in Very Old Subjects: A Real-Life Study. J Nutr Health Aging. 2022;26(3):290-296, https://doi.org/10.1007/s12603-022-1756-1 